\title{
Karatê e agressividade: possíveis relações
}

\section{Karate and aggression: possible relation}

\author{
Cláudio Delunardo Severino ${ }^{1}$ \\ Andressa de Oliveira Barbosa ${ }^{2}$
}

Artigo
Original

Original

Paper

Palavras-chave:

Karatê

Agressividade

Relações

\section{Resumo}

O presente estudo objetiva analisar possíveis relações entre a prática do Karatê e o comportamento, algumas vezes, agressivo por parte de seus adeptos. Para tal, investigaram-se as linhas teóricas do Karatê, seu histórico, ensino, conceitos e as suas abordagens gerais e, sendo assim, buscou-se compreender como os professores de Karatê trabalham com seus alunos a questão da agressividade, bem como as suas consequências. Além disso, procurou-se estabelecer uma maior compreensão acerca da agressividade, bem como suas principais características e conceitos específicos. A metodologia empregada tratou-se de uma pesquisa exploratória, discursiva, de cunho bibliográfico, além de pesquisa de campo para coleta de dados. $\mathrm{O}$ instrumento para a coleta de dados foi um questionário contendo perguntas acerca do desenvolvimento do Karatê, por parte dos professores, e também a relação destes com a temática da agressividade, através do qual delineamos a pesquisa a fim de obter o subsídio necessário para a análise proposta. Os participantes da pesquisa tiveram as suas respostas analisadas para que as mesmas pudessem ser generalizadas e projetadas, identificando-se a melhor forma de aproveitar as informações. Considerando que existem possíveis relações entre a prática do Karatê por crianças e adolescentes e o comportamento agressivo, eventualmente, apresentado pelos mesmos. A elaboração deste estudo justifica-se pela relevância de investigações relacionadas às linhas teóricas do Karatê. Consideramos também os aspectos culturais associados à agressividade e à contribuição que os seus resultados possam vir a apresentar aos profissionais ligados ao processo de ensino-aprendizagem desta arte marcial. Alguns professores consideram que condutas agressivas podem contribuir para o rendimento do aluno, e é esse equívoco que faz com que o indivíduo não seja capaz de lidar com o insucesso, ocasionando algumas vezes ações agressivas e até mesmo a violência. Sendo assim, notamos que podem existir relações entre a prática do Karatê e a agressividade, mas que não é o esporte o causador direto desse comportamento agressivo.

${ }^{1}$ Professor graduado em Licenciatura Plena em Educação Física; Pós-graduado em Docência para o Ensino Superior; Mestre em Ensino em Ciências da Saúde e do Meio Ambiente - Centro Universitário de Volta Redonda - UniFOA

${ }^{2}$ Discente do $6^{\circ}$ período dos Cursos de Educação Física do UniFOA - Bacharelado e Licenciatura

Recebido em 05/2011

Aprovado em $08 / 2011$

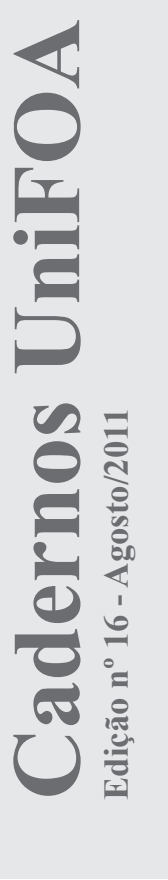


The present study aims to analyze possible relations between the practice of Karate and the aggressive behavior on the part of its adepts. The theoretical lines of the Karate, description, education, concepts and general border has been investigated, and thus searched in order to understand how the Karate teachers can work with their pupils the question of aggression and its consequences. Moreover a better understanding concerning aggression as well as its main characteristics and specific concepts were done. An exploratory, discursive, in a bibliographical matrix and a data collection were employed. The instruments to the data collection was a questionnaire about the development of Karate, by the teachers, and also the relation between them and the aggression topic, and through these we delineate the research in order to get the necessary subsidy to the proposed analysis. The participants in the research had their answers analyzed in a way that they could be generalized and projected, identifying the best form to use its information. Considering that there are possible relation between the practice of Karate by children and adolescents and the aggressive behavior eventually presented by them, the elaboration of this study is justified by the relevance of inquiries related to the theoretical lines of Karate. We also consider the cultural aspects associated to aggression and the contribution that its results can present to the professionals related to the teaching and learning process of this martial art. Some teachers consider that the aggressive behaviors can contribute to the income of the pupil, and this mistake makes the individual not able to deal with failure, sometimes causing aggressive actions even though violence. Thus, we notice that some relation between the practice of Karate and aggression can exist but the sport is not the guilt for this aggressive behavior.

Karate

Aggression

Relations

\section{Introdução}

O Karatê é uma arte marcial praticada em todo mundo e que, com o tempo, tornouse também uma modalidade esportiva. Isso faz com que os professores de Karatê venham a se tornar também técnicos, podendo exercer influências positivas ou negativas sobre seus atletas.

Ao entender que existem possíveis relações entre a prática do Karatê por crianças e adolescentes e o comportamento agressivo eventualmente apresentado pelos mesmos, a elaboração deste estudo justifica-se pela relevância de investigações relacionadas às linhas teóricas do Karatê e à contribuição que os seus resultados possam vir a apresentar aos profissionais ligados ao processo de ensinoaprendizagem da referida arte marcial.

O presente estudo objetiva analisar possíveis relações entre a prática do Karatê e o comportamento, algumas vezes agressivo, por parte de seus adeptos. Para tal, investigaramse as linhas teóricas do Karatê, seu histórico, ensino, conceitos e as suas abordagens gerais e, sendo assim, buscou-se compreender como os professores de Karatê trabalham com seus alunos a questão da agressividade, além de suas consequências. Procurou-se também estabelecer uma maior compreensão acerca da agressividade, bem como suas principais características e conceitos específicos.

O estudo é caracterizado por uma revisão bibliográfica de cunho descritivo acerca do objeto de investigação. Além disso, foi feita uma pesquisa quali-quantitativa com o intuito de abranger a relação entre o contexto e o processo. Sendo assim, o instrumento para a coleta de dados foi um questionário contendo perguntas acerca do desenvolvimento do Karatê por parte dos professores e também a relação destes com a temática da agressividade.

Para Vianna (1996), a partir da compreensão de que a prática do Karatê pode representar riscos para o praticante e para a sociedade, torna-se necessária a realização de pesquisas que abordem a cultura dos praticantes de Karatê e suas consequências individuais e coletivas. 


\section{Metodologia}

O estudo é caracterizado por uma revisão bibliográfica, de cunho descritivo, acerca do objeto de investigação, no sentido de apresentar os conceitos obtidos por outros autores. Além disso, foi feita uma pesquisa qualiquantitativa com o intuito de abranger a relação entre o contexto e o processo. O processo refere-se a como o desenvolvimento acontece e o contexto no qual ele ocorre.

Sendo assim, o instrumento para a coleta de dados foi um questionário contendo perguntas acerca do desenvolvimento do Karatê por parte dos professores e também a relação destes com a temática da agressividade.

Para a realização da pesquisa, foram contactados diversos professores de Karatê que atuam na região Sul Fluminense do estado do Rio de Janeiro, além de profissionais de outros estados, participantes do Campeonato Brasileiro da Federação Brasileira de Karatê (FBK), realizado na cidade de Duque de Caxias-RJ em 2010. O período de realização da pesquisa ocorreu entre os meses de março e setembro de 2010 e o questionário foi respondido por 33 professores.

A análise dos dados foi desenvolvida de acordo com os resultados obtidos por meio do instrumento de coleta de dados. Os participantes da pesquisa tiveram as suas respostas analisadas para que as mesmas pudessem ser generalizadas e projetadas, identificando a melhor forma de se aproveitar as informações.

\section{Agressividade e Violência}

A agressividade é característica de atuação normal em fase inicial do desenvolvimento do indivíduo (SANTOS, 2008). Tal comportamento, embora possa ser transitório ou efêmero, pode ter suas consequências refletidas durante toda a vida do indivíduo.

Goldberg (2004, p. 22), em seus apontamentos voltados para a violência, cita Einstein, que disse que a "violência fascina os seres moralmente mais fracos". Para Gauer (2008), a agressão e a impulsividade estão relacionadas à violência que encontramos em nossa sociedade e são multifatoriais, não tornando, por isso, tal comportamento completamente elucidado.
Sobre a violência, Birman (2009, p. 61) afirma que:

Não resta dúvida de que a violência é uma marca que perpassa a história humana, estando presente não apenas em diversas tradições culturais como também em todas as sociedades. Não obstante as múltiplas diferenças existentes nessas e naquelas, nos registros político, religioso e simbólico, a violência está sempre lá, como traço indelével da experiência social, regulando e desregulando ao mesmo tempo as relações entre as subjetividades. Trata-se, enfim, de uma invariante que caracteriza a história social de maneira irrefutável

O autor supracitado observa que é necessário destacar que se pode constatar a existência, na atualidade, de formas inéditas de violência, que ultrapassam tudo o que nos antecedeu historicamente. As novas modalidades de violência não apenas agridem a sociedade, mas principalmente chocam, devido a sua intensidade. Birman (2009, p. 61) também aponta que "nos registros - social, político, militar, familiar e amoroso- a violência se revela com tais características. Daí sua originalidade, que evidencia ainda por sua disseminação e por sua banalização".

Porém, diferente da violência, que é a aplicação intencional de uma ação para fins destrutivos e/ou prejudiciais ao outro, Santos (2005) define a agressividade como uma reação relacionada com a imaginação, o pensamento e ações, podendo estas ocorrerem de formas verbais ou não verbais.

Mas como a agressão se manifesta no homem?

Segundo Morris (2008), o organismo se prepara para uma ação por meio do sistema nervoso autônomo, que se subdivide em dois subsistemas: simpático e parassimpático. O subsistema simpático é responsável pela preparação para atividades consideradas violentas, enquanto o segundo possui a função direta de manter e reconstituir as reservas do corpo. De acordo com mesmo autor, na maioria das ocasiões, o organismo responde aos dois subsistemas. Porém, num momento de agressividade, o corpo responde apenas ao sistema sim- 
pático que, estimulado, aumenta a adrenalina, afetando assim todo o sistema circulatório.

Morris (2008, p. 158) complementa:

O coração bate mais depressa e o sangue que circula na pele e nas vísceras é desviado para os músculos e para o cérebro. A pressão arterial aumenta. Acelera-se a produção de glóbulos vermelhos. O sangue coagula mais rapidamente do que em condições normais. Além disso, interrompem-se os processos de digestão e de armazenamento de alimentos. A salivação é inibida, assim como os movimentos do estômago [...] A atividade respiratória aumenta. A respiração torna-se mais rápida e profunda. Os cabelos põem-se em pé e há intensa sudação.

Quanto à agressividade no esporte, na perspectiva de Samulsky (1992), este é o campo social em que há a maior importância acerca do confronto físico entre indivíduos. Associando essa consideração à agressividade, Gabler (1987, p. 94 apud SAMULSKY, 1992, p. 101) a define como:

Uma disposição permanente (motivo) de uma pessoa para comportar-se numa determinada situação de forma agressiva. Um comportamento é denominado agressivo quando existe só uma intenção ou o desejo de prejudicar outra pessoa independentemente da realização da ação agressiva e dos efeitos prejudiciais pretendidos.

Próximos a esta definição, Baron e Richardson (1994, p. 7 apud WEINBERG; GOULD, 2008) consideram que a agressividade pode ser considerada como qualquer forma de comportamento que apresente "o objetivo de prejudicar ou ferir outro ser vivo que está motivado a evitar tal tratamento".

Weinberg e Gould (2008) entendem que a agressividade é caracterizada por um comportamento verbal ou físico, não devendo ser interpretado como uma simples atitude ou emoção. Além disso, tal comportamento também apresenta a evidência do envolvimento de danos ou ferimentos que podem ser psicológicos ou físicos.
Isso posto, percebemos a necessidade de investigar possíveis causas e consequências do comportamento agressivo em modalidades esportivas, aqui, especificamente, o Karatê.

\subsection{Teorias da agressão}

Samulsky (1992) estabelece algumas teorias relacionadas ao comportamento agressivo. A primeira delas é a de instintos e impulsos, quando o autor observa que a agressão é proveniente de um instinto inato e espontâneo, provocando assim um acúmulo contínuo de energia agressiva no organismo e que, por necessidade, deve ser eventualmente descarregada. Para Gill (2000 apud WEINBERG; GOULD, 2008), quanto a essa mesma teoria, o indivíduo tem um instinto inato voltado para a agressividade que se desenvolve até o momento em que ele seja manifestado diretamente ou por meio de catarse, em que a agressividade é exposta por intermédio de ações socialmente aceitáveis.

$\mathrm{Na}$ teoria frustração-agressão, também conhecida como teoria do impulso, há a hipótese de que situações relacionadas a algum tipo de frustração possam ocasionar agressões. Nesse caso, a frustração é definida "como um impedimento de uma atividade atual dirigida a uma meta" (SAMULSKY, 1992, p. 99).

$\mathrm{O}$ referido autor ressalta que:

$$
\begin{aligned}
& \text { O objetivo do comportamento agressi- } \\
& \text { vo é prejudicar intencionalmente outra } \\
& \text { pessoa ou outro objeto. Frustrações não } \\
& \text { provocam automaticamente condutas } \\
& \text { agressivas. Comportamento agressivo é } \\
& \text { uma das reações possíveis em presença } \\
& \text { de frustrações. Outras reações são, por } \\
& \text { exemplo, regressão, resignação e de- } \\
& \text { cepção (p. 99). }
\end{aligned}
$$

Nessa teoria, a agressividade é compreendida como o resultado direto de uma frustração ocasionada pelo fracasso do objetivo (DOLLARD et al, 1939 apud WEINBERG; GOULD, 2008).

Samulsky (1992) complementa que a conduta agressiva está relacionada a tendências agressivas, causas da frustração e intensidade das frustrações passadas, além da quantidade e intensidade das mesmas. Entretanto, essa te- 
oria, atualmente, vem perdendo adeptos, pois, segundo Weinberg e Gould (2008), pesquisas e experiências comprovam que os indivíduos em diversas ocasiões convivem com suas frustrações ou as demonstram de maneiras pouco o nada agressivas.

Outra teoria voltada para a questão da agressividade é a da aprendizagem social, que entende essa questão como um comportamento o qual o indivíduo assimila comportamentos agressivos por meio da observação de outros, exibindo assim atitudes semelhantes. Segundo Weinberg e Gould (2008), a observação da violência na mídia se encontra diretamente relacionada a algumas atitudes agressivas, sugerindo que, por esse caminho, as pessoas, em especial as crianças, são expostas a inúmeras situações de violência, aprendendo assim diversas maneiras de serem agressivos.

Essa teoria reforça o importante papel que alguns elementos, dentre eles os professores, possuem acerca do controle do comportamento agressivo, tendo em vista não somente a sua capacidade de influência, mas a percepção de que a modelagem é uma maneira veemente de se assimilar comportamentos agressivos ou não.

\subsection{As causas da agressividade}

Samulski (1992) aponta fatores importantes para a existência de posturas agressivas por parte de atletas, entre eles, o nível de rendimento dos mesmos e o comportamento dos técnicos. Balbino et al (1997 apud TRAMONTIN; PERES, 2008) também elencam algumas causas de comportamentos agressivos envolvendo atletas, incluindo as pressões exercidas pelos técnicos e a questão financeira.

Percebemos que os autores acima citados mencionam em seus respectivos estudos a influência que o técnico pode exercer sobre seus alunos/atletas. Consideramos que esse fato deva ser sempre levado em consideração quando se trata de uma preparação esportiva relacionada a qualquer modalidade, bem como a precaução que o professor deve ter ao abordar a questão da agressividade junto aos seus alunos.

$\mathrm{Na}$ perspectiva de Weinberg e Gould (2008), muitos técnicos e atletas acreditam que a agressão contribui para a melhora do rendimento, na maioria das vezes por meio de ameaças e ações intimidadoras em relação aos adversários, garantindo assim, a diminuição do rendimento destes em contraste com a autopreservação do agressor. Percebemos que se tal postura esteja baseada em orientações vindas por parte dos técnicos, a agressividade encontrará cada vez mais na prática esportiva um dos seus principais alicerces.

\section{Karatê e Agressividade}

Santos (2005) afirma que são cinco os mandamentos do Karatê-Dô: a formação do caráter do praticante, a sabedoria e o senso de justiça, a formação ética na produção de resultados, a formação do respeito à hierarquia e às regras sociais e a reprovação dos atos de violência. Mesmo reconhecendo a importância de todos os mandamentos no que tange à formação global do praticante do Karatê, consideraremos apenas o quinto, a reprovação dos atos de violência, por ser o mais relevante a respeito do presente estudo.

Santos (2005, p. 6) o aponta na seguinte interpretação:

Pronúncia em japonês: Hitotsu. Kekki no Yu o Imashimuru Koto. Em português: Sempre. Conter o espírito de agressão destrutiva. O Karatê-Dô Tradicional cultua a não agressão destrutiva. Trabalha-se o controle da agressividade, redobrando-se o cuidado nos treinos e atividades, colocando o estado de atenção não apenas conosco, mas também com o outro. Respeitando-se sempre a dignidade de todo ser humano.

Para que o controle acima mencionado esteja sempre presente nas atividades voltadas para a prática dessa arte marcial, as suas regras impõem um rígido controle. Além do código de ética do Karatê-Dô Tradicional, o Dojo Kum, a modalidade também possui os regulamentos da Federação Internacional de KaratêDô Tradicional - ITKF e os da Confederação Brasileira de Karatê-Dô Tradicional - CBKT, além das Federações Estaduais e diversas Associações. As punições para ações como violação premeditada, desrespeito ao professor ou conduta agressiva, associadas ou não às atividades ligadas ao Karatê, podem ir da

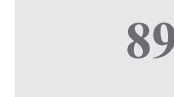

.


advertência verbal à exclusão, conforme podemos perceber nas regras estabelecidas pelos parâmetros oficiais da CBKT (1997 apud SANTOS, 2005, p. 12):

I - Violação premeditada e deliberada das regras da categoria de competição; II - Agitação ou emoção excessiva que ameace a continuação segura da luta; III - Recebimento de duas advertências graves enquanto compete na mesma categoria na competição; IV - (...) por falta de habilidade para competir. Isto indica que o competidor não tem habilidade suficiente (...).

Além desse controle feito pelas regras e pelo código de ética do Karatê-Dô, esta modalidade apresenta, como uma de suas características, a disposição evidente em assegurar que o comportamento agressivo não é tolerado, punindo os seus praticantes que agem de maneira agressiva (WIDMEYER apud WEINBERG; GOULD, 2008). É importante ressaltar que essa punição não revela a consciência de estar lidando com um culpado, mas sim, com um causador de danos. No entendimento de Nietzsche (2009, p. 64), isso nos leva à reflexão de que "o castigo teria valor de despertar no culpado o sentimento de culpa".

Santos (2005) observa, ainda, que o adversário jamais deva ser tratado como um inimigo, e que qualquer abuso verbal ou contato que cause dano à integridade física a este é motivo suficiente para a aplicação das sanções presentes nas regras oficiais.

Percebendo ainda a preocupação com que o Karatê sempre teve com o comportamento agressivo, Funakoshi (2005), em seus princípios fundamentais do Karatê, observa que essa arte marcial não deve ser usada injusta ou inadequadamente. "Seus praticantes devem permanecer do lado da justiça em todas as ocasiões e apenas em situações em que não haja outra escolha devem expressar a sua força pelo uso das mãos e dos pés como armas" (FUNAKOSHI, 2005, p. 30).

A formação do Karatê baseia-se na experiência de esvaziamento que, gradativamente, o praticante deve fazer (BARREIRA, 2006). O mesmo autor observa que, de acordo com o relato de diversos mestres, invariavelmente, o principiante compreende o Karatê como uma possibilidade de fortalecimento que o leva a ir ao encontro com situações de agressividade e violência, concepção que não costuma suportar alguns anos de prática. Esses mesmos mestres observam que o praticante se coloca entre duas claras alternativas, que é a transformação dessa concepção ou o abandono do Karatê.

Funakoshi (1994, p. 112 apud BARREIRA, 2006, p. 111) observa que, acerca disso:

[...] sempre há aqueles que têm como desejo único aprender Karatê para utilizá-lo numa luta. [...] Esses quase inevitavelmente abandonam o curso, porque é quase impossível que qualquer jovem com objetivo tão tolo continue por muito tempo no Karatê.

Para Barreira (2006), a partir do momento em que o praticante do Karatê enfatiza a agressividade durante o kumitê, isso implica poucas condições de controle, tanto no plano pessoal como no interpessoal. O tempo de prática, bem como certa quantidade de kumitês assumem a condição de estabelecer a necessidade de reflexão acerca disso.

Por meio dessas observações, percebemos que o professor, amparado nos próprios conceitos filosóficos do Karatê, pode cumprir importante papel no que tange à percepção de comportamentos que, caracterizados pela agressividade, apresentam sérios problemas ao desenvolvimento biopsicossocial do praticante. Diante disso, notamos a necessidade do professor em assumir o compromisso de, ao observar tais comportamentos, não abrir mão da sua responsabilidade de indicar os rumos que se deseja para uma sociedade mais justa e com igualdade de oportunidades, o que certamente, a prática consciente de uma modalidade como o Karatê contribuirá de forma positiva se for aplicada de maneira coerente.

\section{Análise e Discussão de Resultados}

A pesquisa acerca do desenvolvimento do Karatê por parte dos professores e também a relação destes com a temática da agressividade foi norteadora para se alcançar alguns 
resultados. Esses resultados foram obtidos a partir dos dados coletados por intermédio da pesquisa e dos conceitos desenvolvidos na revisão bibliográfica.

Acerca da formação dos professores que responderam o questionário associado a esta pesquisa, dados incluídos no Gráfico 1, apontam que, dos 33 participantes, 11 são graduados em Educação Física, além de 7 com especialização (lato sensu). Contudo, os resultados indicam que 15 professores apresentam como formação o título de mestre em Karatê (4) ou outras especificações, como por exemplo, a condição de ex-atletas.

Atualmente, existem casos que apontam decisões judiciais favoráveis a não cobrança de registros nos Conselhos Regionais ou Federal de Educação Física (CREF e CONFEF). Porém, entendemos ser relevante o estabelecimento de conceitos que abordam o papel do professor de Educação Física e as circunstâncias que o envolvem, além da sua importância dentro da própria prática docente.

No entendimento de Magalhães e Arantes (2007), espera-se que docente de Educação Física esteja apto em relação ao que a práxis exigirá. Ele deve, acerca das aulas, planejar e disseminar conhecimentos relacionados à construção de um saber ligado à motricidade humana. Contudo, mesmo sendo um especialista em movimento, é necessário que se observem outras dimensões humanas. Então, para que as aulas e treinamentos de modalidades esportivas atinjam os seus objetivos, torna-se interessante que se aprofunde os estudos além do aspecto motor, itens tais como a relação interpessoal, a liderança e a comunicação.

Piaget apud NEIRA (2006) considera a atuação do professor indispensável na medida em que deve ter um papel ativo na estruturação do processo de aquisição de conhecimento de seus alunos, ajudando-os a construir e organizar suas ideias, ampliando-lhes o olhar, sempre que possível, e estimulando a pesquisa e as ações. O papel do professor é fundamental, sendo que suas atitudes interferirão na relação que este irá estabelecer com o conhecimento. O professor capacitado é aquele que apresenta o nível do desafio proposto, devendo, portanto, saber gerenciar o que acontece e tornar o meio o mais favorável possível para reflexões e descobertas (NEIRA, 2006).
Em observação feita pelo autor supracitado, a formação adequada do professor é fator fundamental, uma vez que corresponde a um dos eixos básicos da educação: formar os futuros cidadãos de uma sociedade; cidadãos, em princípio, comprometidos com valores de sua cultura, com os saberes acumulados, e, ao mesmo tempo, cidadãos atualizados com técnicas e problemas, em função de projetos pessoais e coletivos.

Diante disso, Ghiraldelli Junior (2001) complementa com a proposta de que o papel do profissional de Educação Física deva ser o de um agente transformador que estabeleça uma nova direção sócio-política e cultural.

Na prática, isso significa que o trabalho do professor deva ir além da simples transmissão de técnicas esportivas. Torna-se necessário que, a partir de ações pedagógicas promovidas diretamente pelo professor, a aula seja transformada num ambiente onde a cultura se estabeleça como um caminho para o desenvolvimento crítico por parte dos discentes.

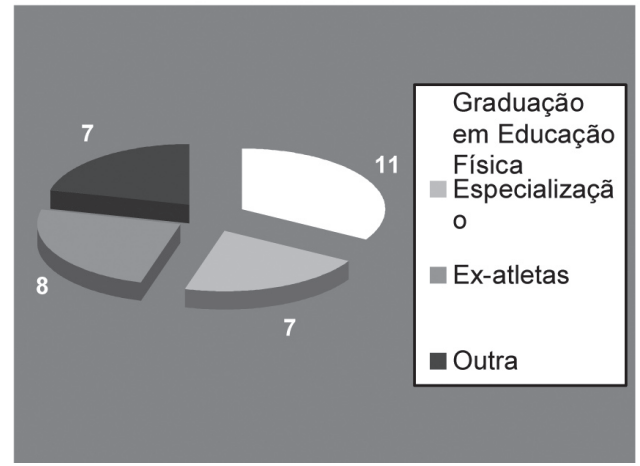

GRÁFICO 1 - Resultados relacionados à formação dos professores participantes da pesquisa.

A análise referente à priorização das lutas (kumitês) aplicada em aulas indica que 18 dos professores entrevistados priorizam as lutas durante as aulas por meio de simulação de competições. Dos outros participantes, sete não priorizam as lutas, cinco o fazem por intermédio de práticas recreativas e apenas três trabalham as lutas de outras formas, como por exemplo, por meio de combinações de golpes de ataque e defesa (Gráfico 2).

Para Ferreira (2006), a prática de tal ação pode trazer inúmeros benefícios ao usuário, destacando-se o desenvolvimento motor, o cognitivo e o afetivo-social. O mesmo autor complementa (2006, pp. 4-5): 
No aspecto motor, observamos o desenvolvimento da lateralidade, o controle do tônus muscular, a melhora do equilíbrio e da coordenação global, o aprimoramento da ideia de tempo e espaço, bem como da noção de corpo. No aspecto cognitivo, as lutas favorecem a percepção, o raciocínio, a formulação de estratégias e a atenção. No que se refere ao aspecto afetivo e social, podese observar em alunos alguns aspectos importantes, como a reação a determinadas atitudes, a postura social, a socialização, a perseverança, o respeito e a determinação.

O fato de grande quantidade de professores (18) trabalharem as lutas por intermédio de simulação de competições evidencia duas questões. A primeira delas e atribuída ao imenso fascínio que as lutas provocam nos alunos (Ibid, 2006). Além disso, outro aspecto a ser considerado é a forte penetração que a competição exerce no cotidiano.

Nessa perspectiva, Bourg apud Assis (2005) afirma que, na competição, é preciso vencer a qualquer custo. $O$ público anseia por vitórias que elevam os atletas à condição de verdadeiros heróis patrocinados por grandes empresas, que investem em tecnologia para esses homens se superarem cada vez mais e venderem cada vez mais os seus produtos, fechando-se o ciclo.

Kunz e Trebels (2006), mesmo reconhecendo a relevância da prática do esportecompetição, também defendem que a prática por si só não é capaz de formar um cidadão e que o esporte não deve ser visto somente com bons olhos, já que, muitas vezes, os indivíduos não se dão conta das situações ocorridas como as tentativas de burlar as regras, a exclusão das pessoas menos habilidosas, as constantes tentativas de levar vantagem e os negócios e vícios da publicidade. Portanto, se faz necessário prever quais são as possibilidades de aprendizado daquele conteúdo, inclusive os ocultos, e, quais os objetivos deverão será alcançados, para que se possa então utilizar as práticas esportivas.

Contrariando essa abordagem, Dietrich e Landau apud Kunz e Trebels (2006), partem do princípio de que o esporte não é algo naturalmente oferecido aos seus praticantes, mas sim, uma forma de construção social. Eles defendem a ideia de que o esporte deve desenvolver uma estrutura cognitiva para que assim os praticantes possam entender as opressões sociais que existem ocultas no esporte, com isso, eles defendem a ideia de que as interações no esporte não devem acontecer ao acaso e sim planejadas com tal objetivo.

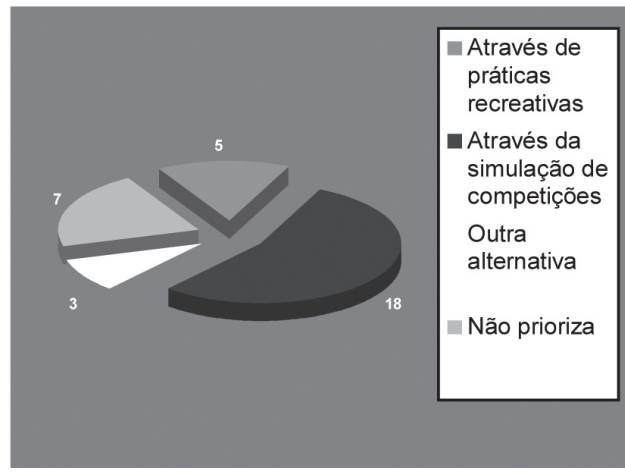

GRÁFICO 2 - A prioridade das lutas nas aulas de Karatê.

Como dissemos anteriormente, a violência é caracterizada pela utilização desejada da agressividade para fins destrutivos. Para Santos (2005), a agressividade está na constituição da violência, porém, não é o único fator que a justifica. A inclusão dessa questão no instrumento de avaliação associado a esta pesquisa justifica-se pelo fato de percebermos que a crescente violência, descontrolada, pode mobilizar no indivíduo um comportamento agressivo na condição de uma ação destrutiva por parte dos praticantes do Karatê.

Biaggio (1991 apud SANTOS, 2005, p. 11) acrescenta:

Como o aumento progressivo nas últimas décadas dos instrumentos de destruição, como as circunstâncias da vida urbana e da superpopulação nas grandes cidades, o potencial destrutivo do homem tornou-se ainda mais perigoso.

Mesmo reconhecendo que as regras oficiais do Karatê e o seu próprio código de ética possuem normas rígidas contra a prática de ações agressivas por parte dos praticantes, percebemos, conforme dados apresentados no Gráfico 3, que mais da metade dos parti- 
cipantes (17) consideram que a presença de ações violentas nesta modalidade depende do professor. Sendo assim, a postura do professor pode ser o principal caminho para que, no combate à violência, os impulsos agressivos sejam controlados.

Um dos objetivos do professor deve ser o de promover ações em que os seus alunos, além de assimilar os movimentos específicos do Karatê, percebam, com prazer, a razão de executar os mesmos. Contudo, apresenta-se como questionável a metodologia utilizada para se alcançar tal propósito.

Consideramos que muitos professores ainda necessitam da percepção de que o ato de ensinar não se limita apenas a transmitir conteúdos. Ensinar deve estar ligado ao ato de educar, a contribuir para o despertar da consciência crítica do indivíduo, oportunizando um maior juízo de valores, uma visão de mundo mais ampla e o um maior discernimento acerca das questões sociais.

Sendo assim, percebe-se que o professor, consciente da importância do seu papel, não pode contentar-se com a educação bancária, ou seja, não deve se limitar apenas à transmissão de conteúdos para que os mesmos possam ser assimilados e arquivados pelos alunos (FREIRE, 2008). Deve, também, despertar nos seus alunos a consciência crítica e um pleno exercício da cidadania. Neste caso, partindo desse exercício, o professor passa a assumir uma postura que contribui efetivamente para o repúdio à crueldade, incentivando os seus alunos ao combate a todas as formas de agressividade.

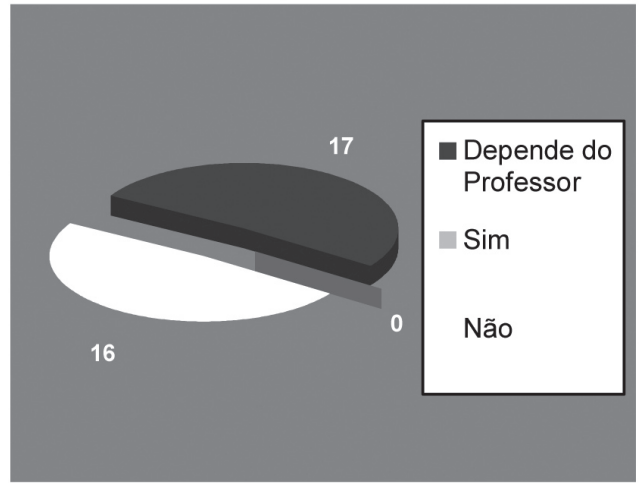

GRÁFICO 3 - Relação da prática do Karatê com a agressividade.

Em relação aos alunos se tornarem mais agressivos ao praticarem lutas, 29 dos parti- cipantes da coleta de dados responderam negativamente a essa questão, enquanto 4 professores apenas consideram tal possibilidade. (Gráfico 4).

Sousa et al (2010) observam que a tradição das artes marciais, de origem oriental, valoriza princípios de não agressão e condenam a violência, devendo o combate ocorrer apenas em última instância. Contudo, esse conceito carece de rigor e análise científica para que possa ser verificada e enunciada com propriedade.

Com a popularização do Karatê que cada vez mais se afirma como desporto de combate e com todas as características desportivas que lhe são atribuídas, essa arte marcial obteve outras necessidades que excedem os ensinamentos originais, sendo questionável em alguns aspectos, como por exemplo, a necessidade da vitória enfatizada por alguns professores.

Os dados identificados no Gráfico 7 contrastam, de certa maneira, com os resultados obtidos pela pesquisa realizada por Sousa et al (2010), na qual verificase que os praticantes de Karatê apresentam valores mais elevados na dimensão agressão física quando comparados com um grupo de não praticantes.

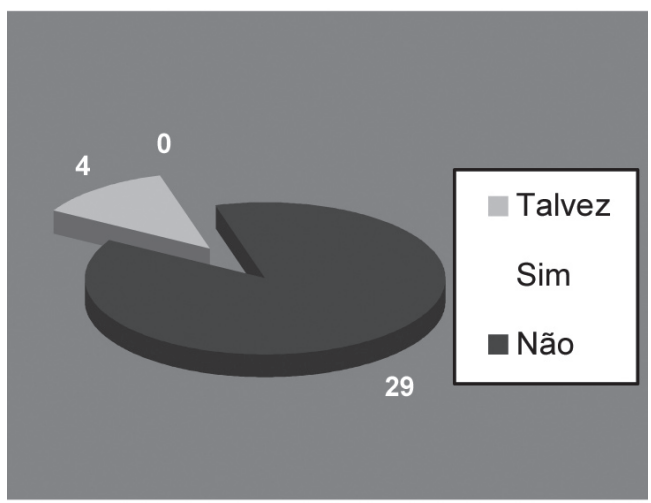

GRÁFICO 4 - A relação entre a prática da luta e o comportamento agressivo por parte dos alunos.

A importância da mídia no mundo atual é, para Betti (2003), evidente. Sendo assim, a sua influência acaba por ditar conceitos acerca de práticas corporais, reproduzindo-as, transformando-as e constituindo novas modalidades de consumo (BETTI, 2003). Diante de tal afirmação, percebemos a necessidade, por parte do professor, de estabelecer a busca pela compreensão dessa questão e como lidar com ela no cotidiano profissional. 
Quando foram questionados se durante as aulas, os alunos costumam associar a luta a situações de violência apresentadas na mídia, 27 dos professores entrevistados afirmaram que não, enquanto apenas 6 responderam afirmativamente (Gráfico 5). Um resultado até certo ponto curioso, partindo da premissa de que as mídias estão em toda parte e nos concedem inúmeras informações por intermédio de imagens, sons e palavras.

No que tange às lutas de maneira geral, Ferreira (2006, p. 5) afirma que:

Nos dias atuais, constata-se que o tema está em moda, seja em desenhos animados, em filmes ou em academias. Não é difícil encontrar crianças brincando de luta nos intervalos das aulas ou colecionando figurinhas dos heróis que lutam em seus desenhos animados. Os adolescentes compram revistas que se referem ao tema, adquirem livros de técnicas de luta e matriculam-se em academias para realizar a prática da luta.

É necessário considerar que, mesmo se dizendo neutras, as mídias se amparam numa linguagem audiovisual que alimentam o imaginário coletivo. Porém, principalmente em se tratando de crianças, ela pode ser uma influência negativa. Para Train apud Bittencourt (2000), quanto mais novas as crianças, mais suscetíveis elas serão às influências da mídia. Podemos entender essa situação devido ao fato de que, para a criança, nem sempre é possível diferenciar a realidade da fantasia.

No entendimento de Bittencourt (2000), quanto mais a criança agressiva é exposta às ações de violência mostradas na mídia, mais ela se identificará com os personagens ali apresentados, pois são semelhantes aos atos vivenciados por ela. Neste caso, a mesma autora conclui que a criança começa a aceitar soluções violentas para a resolução de seus problemas e conflitos.

Nesse contexto, percebemos que mesmo que a maioria dos professores participantes não considere tal realidade, é necessário refletir sobre as consequências da influência da mídia não somente para o Karatê, mas também para a educação em geral.

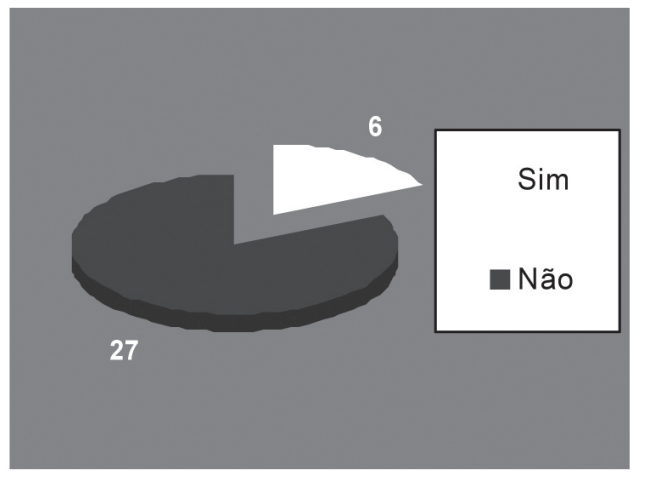

GRÁFICO 5 - A associação da luta com situações de violência apresentadas na mídia.

Acerca da realização de trabalhos voltados para a questão da agressividade com os alunos, o Gráfico 6 indica que 26 participantes os realizam constantemente, 4 o fazem esporadicamente e 3 executam poucas ações no que tange a este tema.

Consideramos que a prática do Karatê pode ser compreendida como uma possibilidade reprodutora de manifestações de agressividade, as quais podem ser desencadeadas por alguns fatores como relações interpessoais, características individuais, o contexto social o qual o aluno está inserido e a mídia. Nesse caso, quando o professor não promove ações que não lhe oportunizam a lidar com a agressividade, isso poderá acarretar um aumento do contexto da agressão (CANDREVA et al, 2007).

Compete aos professores- no entendimento de Candreva et al (2007), por meio de ações contextualizadas- produzirem a compreensão, por parte de seus alunos, e que priorizem o ser humano na sua globalidade, contribuindo para a superação do conceito de que as artes marciais, aqui em especial o Karatê, remetem o seu praticante à apresentação de um comportamento agressivo.

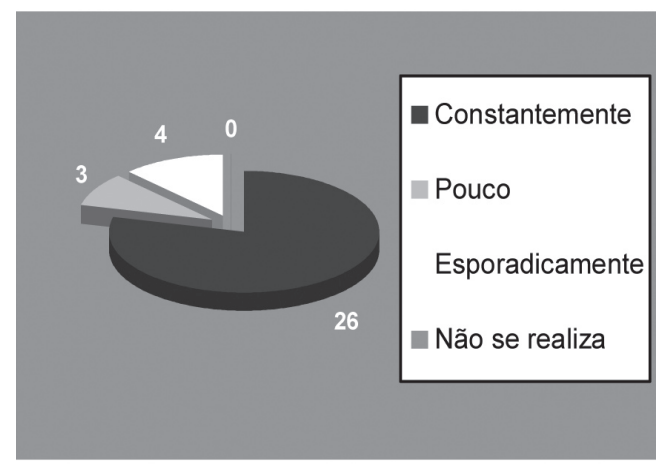

GRÁFICO 6 - Realização junto aos alunos de trabalhos voltados para a questão da agressividade. 
Outro ponto abordado na pesquisa diz respeito à realização de um trabalho de conscientização junto aos pais sobre questões relacionadas à agressividade. Os resultados apresentados no gráfico 7 indicam que 15 dos 33 participantes realizam esse trabalho e 12 o fazem esporadicamente. Dos outros participantes, 4 pouco realizam um trabalho voltado para a conscientização dos pais acerca da agressividade e 2 simplesmente não o fazem.

Nas aulas de Karatê, podemos perceber que, de acordo com o planejamento de professor, os estímulos dados podem propiciar uma variedade de vivências significativas, os objetivos das atividades estimulam no aluno a confiança e integram o mesmo ao meio social.

Esses objetivos podem ser observados pela família por intermédio da convivência e do contato com o professor, quando a postura do aluno vai passando por modificações consideráveis. Tal situação possibilita uma expectativa que se faz presente a partir do momento em que a família se insere de alguma forma no ambiente de treinamento da criança.

Szymanski (2009) evidencia que os encontros entre pais e professores ocorrem primordialmente e em função de problemas comportamentais. Tais contatos entre pais e professores ocorrem por intermédio de uma possível solução, em que o pai torna-se ciente do problema e de certa forma intervém por meio da correção.

O professor, ao tomar determinada atitude, está dando sequência a todo um trabalho de avaliação. Estabelecida tal relação e respeitando-se os valores e a individualidade de cada um, entendemos que ela propiciará futuras melhoras no desenvolvimento global do aluno, em decorrência do trabalho em conjunto.

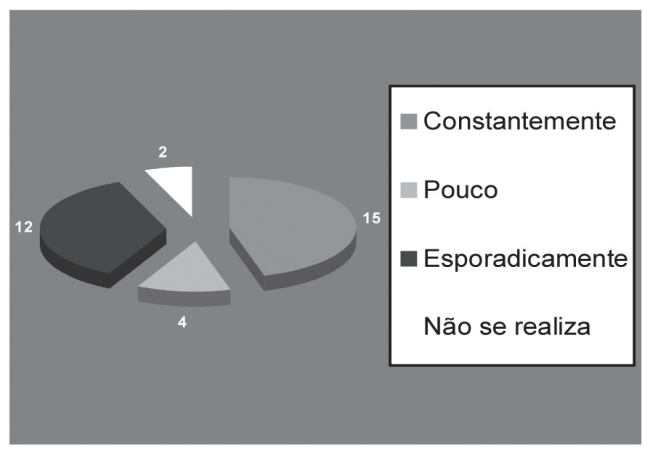

GRÁFICO 7 - Realização junto aos pais de trabalhos voltados para a questão da agressividade.
Conforme os dados apresentados no Gráfico 8, dos 33 participantes da pesquisa, 20 professores consideram que busca por resultados positivos em competições não é associada a comportamentos agressivos por parte dos alunos, enquanto 12 deles acreditam que tal condição depende da postura apresentada pelo professor.

De acordo com Tani et al (2006), alguns pedagogos não apresentam posições favoráveis à presença do desporto na formação de crianças e jovens. Esses pedagogos encaram a competição como o lado mais perverso da prática do esporte, pois oferece aos alunos valores relacionados à concorrência e individualismo. Mesmo assim, os mesmos autores veem, na competição, a possibilidade de a mesma ser um instrumento de aproximação, de cooperação e diálogo entre todos os seus participantes.

Para que a competição tenha sua contribuição na formação de crianças e jovens, segundo Tani, Bento e Petersen (2006), devem-se encontrar propostas mais adequadas para o efeito em fases do processo de desenvolvimento, criar competições para crianças e adolescentes sem exigir o desempenho de modelos de alto nível, organizando formas convenientes de práticas competitivas, a fim de que a mesma possa vir a ter sua contribuição para a formação do jovem.

Marques (2004) afirma que muitos profissionais ligados ao processo educacional apresentam resistência à adoção da prática desportiva como um modelo de formação e educação dos jovens. O mesmo autor aponta que a origem de tal concepção está ligada à competição, considerada por muitos como o aspecto mais perverso do desporto. O principal argumento relacionado a esse quadro aponta para o fato de que a prática formal de atividades esportivas promove a formação de valores distorcidos de concorrência e de individualismo, em detrimento de questões voltadas para a solidariedade, o companheirismo e a igualdade.

O desporto e a competição confundem-se no entendimento do jovem sobre o significado da prática. O principal sentido do desporto para a criança, por exemplo, é a competição (DE ROSE JUNIOR, 2009). Neste caso, tratase da possibilidade que ela - a criança - tem 
de avaliar as suas capacidades, de mostrar, aos outros, aquilo do que é capaz, de se superar.

A competição tem o seu valor independente do contexto o qual está inserido. Porém, ela só poderá encontrar alguma relevância se o seu objetivo for o de preparar os jovens para a vida e contribuir para a formação dos mesmos.

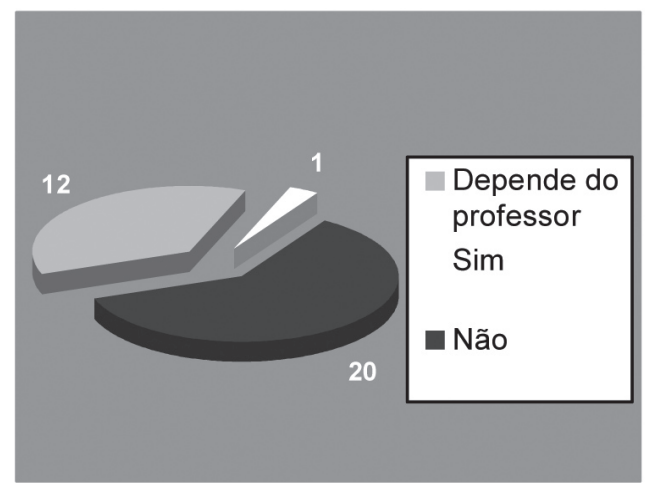

GRÁFICO 8 - A busca por resultados positivos em competições a sua associação a comportamentos agressivos por parte dos alunos.

\section{Considerações Finais}

Consideramos que a prática do Karatê objetiva a formação do indivíduo tanto no que diz respeito ao aspecto físico como moral. Juntamente com a prática desse esporte, estão agregados valores de respeito ao ser humano, autocontrole, disciplina e reprovação aos atos de violência.

Partindo do pressuposto de que um comportamento é considerado agressivo- desde que exista um desejo de prejudicar outra pessoa, sendo este realizado ou não- podemos considerar que o Karatê em si não contribui para esse comportamento, mas que a utilização do mesmo para fins esportivos inadequados pode resultar em condutas agressivas por parte de seus praticantes.

Existem algumas causas para a agressividade, dentre elas a frustração. Alguns professores consideram que condutas agressivas podem contribuir para o rendimento do aluno e é esse equívoco que faz com que o indivíduo não seja capaz de lidar com o insucesso, ocasionando algumas vezes ações agressivas e até mesmo a violência.

$\mathrm{O}$ Karatê não contempla apenas a questão da luta, no entanto, esta tende a ser a grande preferência por parte dos seus praticantes e professores. De acordo com os resultados obtidos pela pesquisa, percebemos que há priorização das lutas por intermédio de simulações de competições, o que, se for realizado de maneira adequada, ou seja, sendo apenas uma preparação para campeonatos, sem que haja uma obrigatoriedade de vencer, não causa frustração e, portanto, não contribui para um comportamento agressivo por parte dos atletas.

As crianças não costumam diferenciar a realidade da fantasia, isso faz com que elas sejam mais suscetíveis a incorporar situações de violência. A mídia tende a exercer grande influência nessas crianças, por meio de desenhos que mostram situações de agressividade e até mesmo filmes de artes marciais que mostram as lutas como pura violência, entretanto, as situações de violência exibidas na mídia não apresentaram grande influência para os praticantes.

A realização de trabalhos a respeito da agressividade é muito importante tanto para os praticantes de artes marciais quanto para os pais. A mídia muitas vezes mostra as artes marciais com situações de agressão física e isso pode formar uma imagem conturbada do que realmente é o Karatê. Indivíduos podem ter uma imagem equivocada do que é essa arte marcial por desconhecerem a sua filosofia e entenderem sua prática meramente como uma luta. Devido a isso, trabalhos, tanto com os alunos quanto com os pais, tornam-se relevantes, pois transmitem conhecimentos acerca do Karatê, reduzindo os possíveis equívocos sobre essa prática, além trazerem os pais para um ambiente onde os filhos passam uma boa parte do tempo.

Como vimos, o Karatê não exerce influência direta sobre comportamento agressivo por parte dos seus praticantes. Tanto as teorias sobre a agressividade quanto os resultados obtidos no questionário mostram que o Karatê não é o responsável por esses comportamentos considerados hostis. A competição exacerbada e a obrigatoriedade de resultados positivos podem causar frustrações nos atletas, podendo ocasionar comportamentos agressivos. Além disso, o técnico, neste caso o professor de Karatê, possui grande influência sobre seus alunos, podendo muitas vezes ser o responsável pelos comportamentos inadequados por parte destes, logo, não devemos atribuir à modalidade esportiva ou a prática de lutas a responsabilidade por esses comportamentos agressivos. 


\section{Referências Bibliográficas}

1. ASSIS, Sávio. Reinventando o esporte: possibilidades da prática pedagógica. 2 ed. Campinas: Autores Associados, 2005.

2. BARREIRA Cristiano Roque. A alteridade subtraída: o outro no esvaziamento do karatê e na redução fenomenológica. 2006. Disponível em: $<$ www.cliopsyche.cjb.net/mnemo/index. $\mathrm{php} / \mathrm{mnemo/article/viewFile/.../180>.}$ Acesso em: 08 Fev. 2010.

3. BETTI, Mauro. (Org.). Educação física e mídia: novos olhares, outras práticas. São Paulo: Hucitec, 2003.

4. BIRMAN, Joel. Cadernos sobre o mal. Rio de Janeiro: Civilização Brasileira, 2009.

5. BITTENCOURT Aline Duran da $\mathrm{S}$. Agressividade: fatores que influenciam negativamente a conduta da criança. 2000. Disponível em: <www.smec.salvador. ba.gov.br/site/.../espaco.../agressividade. pdf>. Acesso em: 08 Fev. 2010.

6. CANDREVA, Thábata et al. A agressividade na educação infantil: 0 jogo como forma de intervenção. 2007. Disponível em: < www.revistas.ufg.br/ index.php/fef/article/.../4695>. Acesso em: 25 Fev. 2010.

7. DE ROSE JUNIOR, Dante. (Org.). Esporte e atividade física na infância e na adolescência: uma abordagem multidisciplinar. 2. ed. Porto Alegre: Artmed, 2009.

8. FERREIRA, Heraldo Simões. As lutas na educação física escolar. 2006. Disponível em: <www.revistadeeducacaofisica.com. br/artigos/2006.3/aslutas.pdf>. Acesso em: 26 Março 2010

9. FREIRE, Paulo. Pedagogia do oprimido. 47 ed. São Paulo, SP: Paz e Terra, 2008.
10. FUNAKOSHI, Gichin. Os vinte princípios fundamentais do karatê: o legado espiritual do mestre. São Paulo: Cultrix, 2005.

11. GAUER, Gabriel Chittó (Coord.). Agressividade: uma leitura biopsicossocial. Curitiba: Juruá, 2008.

12. GOLDBERG, Jacob Pinheiro. Cultura da agressividade. 3. ed. São Paulo: Landy, 2004.

13. GHIRALDELLI JUNIOR, Paulo. Educação Física Progressista: a prática crítico-social dos conteúdos e a educação física brasileira. 7 ed. São Paulo: Loyola, 2001.

14. KUNZ, Elenor; TREBELS, Andreas. Educação Física crítico-emancipatória: com uma perspectiva da pedagogia alemã do esporte. Ijuí: Ed. Unijuí, 2006.

15. MAGALHÃES, Érika; ARANTES, Ana Cristina. A competência profissional e o professor de Educação Física. 2007. Disponível em: <www.efdeportes. com/.../a-competencia-profissional-eo-professor-de-educacao-fisica.htm>. Acesso em: 15 Set. 2010.

16. MARQUES, Antônio. Fazer da competiçao dos mais jovens um modelo de formação e educação. In: GAYA, Adroaldo; MARQUES, Antônio; TANI, Go. Desporto para crianças e jovens: razões e finalidades. Porto Alegre: Ed. da UFGRS, 2004.

17. MORRIS, Desmond. O macaco nu. 17 ed. Rio de Janeiro: Record, 2008.

18. NEIRA, Marcos Garcia. Educação física: desenvolvendo competências. 2 ed. São Paulo: Phorte, 2006.

19. NIETZSCHE, Friedrich Wilhelm. Genealogia da moral: uma polêmica. São Paulo: Companhia das Letras, 2009. 
20. SAMULSKY, Dieter. Psicologia do esporte: teoria e aplicação prática. Belo Horizonte: UFMG, 1992.

21. SANTOS, Ellen Fernanda. Agressividade infantil: possíveis causas e consequências. 2008. Disponível em: <www.revista. inf.br/.../pages/.../edic11anoVInov2008artigo02.pdf $>$. Acesso em: 12 Fev. 2010.

22. SANTOS, José Cirone dos. A legitimação social do karatê-dô tradicional e o controle da "agressividade": um estudo da exclusão da ilicitude na prática esportiva. 2005. Disponível em: <www. sinpoljuspi.com.br/.../ArtigoSobreLeg itimidadeKarat\%EAProfCirone.pdf $>$. Acesso em: 25 Fev. 2010.

23. SOUSA, Oriana et al. Estudo comparativo de agressividade entre praticantes e não praticantes de desportos de combate - karatê. 2010. Disponível em: <www.actassnip2010. com/conteudos/actas/PsiDesp_6.pdf $>$. Acesso em: 25 Fev. 2010.

24. SZYMANSKI, Heloísa. A relação família/escola: desafios e perspectivas. 2 ed. Brasília: Líber Livro, 2009.
25. TANI, Go; BENTO, Jorge Olímpio; PETERSEN, Ricardo Demétrio de Souza. Pedagogia do desporto. Rio de Janeiro: Guanabara Koogan, 2006.

26. TRAMONTIN, Zilmar; PERES, Luís Sérgio. O karatê como ferramenta minimizadora da agressividade no ambiente escolar. 2008. Disponível em: $<$ http://www.diaadiaeducacao.pr.gov. br/portals/pde/arquivos/1933-8.pdf $>$. Acesso em: 13 Abril 2011.

27. VIANNA, José Antônio. Valores tradicionais do karatê: uma aproximação histórica e interpretativa. 1996. Disponível em: <www. boletimef.org/.../BoletimEF.org_ Valores-tradicionais-do-karate-umaaproximacao-historica.pdf $>$. Acesso em: 08 Fev. 2010.

28. WEINBERG, Robert. S; GOULD Daniel. Fundamentos da psicologia do esporte e do exercício. 4. ed. Porto Alegre: Artmed, 2008.
Endereço para Correspondência:

Cláudio Delunardo Severino

claudiodelunardo@gmail.com

Avenida Nove de Julho, 171

Retiro - Volta Redonda - RJ

CEP: 27275-230 